\section{Dynamic regulation of the Ras pathway via proteolysis of the NF1 tumor suppressor}

\author{
Karen Cichowski, ${ }^{1,4}$ Sabrina Santiago, ${ }^{2}$ \\ Melanie Jardim, ${ }^{1}$ Bryan W. Johnson, ${ }^{1}$ and \\ Tyler Jacks ${ }^{2,3}$ \\ ${ }^{1}$ Genetics Division, Department of Medicine, Brigham and \\ Women's Hospital and Harvard Medical School, Boston, \\ Massachusetts 02115, USA; ${ }^{2}$ Department of Biology, Center \\ for Cancer Research, and ${ }^{3}$ Howard Hughes Medical Institute, \\ Massachusetts Institute of Technology, Cambridge, \\ Massachusetts 02139, USA
}

Mutations in the NF1 tumor suppressor underlie the familial tumor predisposition syndrome neurofibromatosis type I. Although its encoded protein, neurofibromin, functions as a Ras-GTPase activating protein (GAP), nothing is known about how it is normally regulated or its precise role in controlling Ras signaling pathways. We show here that neurofibromin is dynamically regulated by the ubiquitin-proteasome pathway. Degradation is rapidly triggered in response to a variety of growth factors and requires sequences adjacent to the catalytic GAP-related domain of neurofibromin. However, whereas degradation is rapid, neurofibromin levels are re-elevated shortly after growth factor treatment. Accordingly, Nf1-deficient mouse embryonic fibroblasts (MEFs) exhibit an enhanced activation of Ras, prolonged Ras and ERK activities, and proliferate in response to subthreshold levels of growth factors. Thus, the dynamic proteasomal regulation of neurofibromin represents an important mechanism of controlling both the amplitude and duration of Ras-mediated signaling. Furthermore, this previously unrecognized Ras regulatory mechanism may be exploited therapeutically.

Received October 29, 2002; revised version accepted December 31, 2002.

Neurofibromatosis type 1 (NF1) is a disorder affecting 1 in 3500 individuals (Riccardi 1992). NF1 patients are predisposed to a variety of tumors of the peripheral and central nervous systems as well as myeloid leukemia, cognitive deficits, bone deformations, and pigmentation defects. In addition, $N f 1$-deficient mice die in utero from heart defects (Brannan et al. 1994; Jacks et al. 1994). Thus, neurofibromin appears to regulate the growth and development of a wide range of cell and tissue types.

Although the NF1 gene was cloned more than 10 years ago, little is known about how neurofibromin normally

[Keywords: NF1; signal transduction; tumor suppressor; Ras; proteasome]

${ }^{4}$ Corresponding author.

E-MAIL kcichowski@rics.bwh.harvard.edu; FAX (617) 732-5123.

Article published online ahead of print. Article and publication date are at http://www.genesdev.org/cgi/doi/10.1101/gad.1054703. participates in cell signaling pathways and growth control (Cawthon et al. 1990; Wallace et al. 1990). Neurofibromin is a $250-\mathrm{kD}$ protein that has sequence similarity to the catalytic domain of p120RasGAP and stimulates the hydrolysis of Ras-GTP in vitro (Ballester et al. 1989; Martin et al. 1990; Xu et al. 1990). Importantly, NF1deficient tumors and primary mouse cells exhibit elevated levels of Ras-GTP, supporting the notion that neurofibromin functions to suppress the Ras pathway in vivo (Basu et al. 1992; DeClue et al. 1992; Kim et al. 1995; Bollag et al. 1996). Nf1-deficient hematopoietic cells are hypersensitive to specific cytokines, suggesting that neurofibromin may function downstream of these receptors (Bollag et al. 1996; Zhang et al. 1998). However, the precise regulatory mechanisms that couple growthfactor receptors to neurofibromin and Ras signaling pathways remain unclear. Boyer and colleagues reported that neurofibromin becomes phosphorylated on serine residues following $\operatorname{Ig} M$ cross-linking, although the biochemical consequences of this modification are unknown (Boyer et al. 1994). Also, specific lipids inhibit neurofibromin GAP activity in vitro, but the importance of this regulation in vivo has not been determined (Bollag and McCormick 1991; Han et al. 1991).

\section{Results and Discussion}

To explore potential neurofibromin regulatory mechanisms, we examined its expression under various cell culture conditions. We found that when quiescent NIH3T3 fibroblasts were treated with serum, neurofibromin rapidly decreased to low or undetectable levels within $5 \mathrm{~min}$ (Fig. 1A). However, within $30 \mathrm{~min}$, neurofibromin levels were re-elevated. Importantly, p120RasGAP protein levels were unaffected under these conditions. Western blots probed with three different antineurofibromin antibodies that recognize epitopes thoughout the protein all demonstrated a rapid reduction in protein levels, indicating that neurofibromin is completely degraded in response to serum (Fig. 1B). Serum triggered neurofibromin degradation in a variety of cell lines, including primary human IMR90 cells and a rat Schwannoma cell line (RT4; Fig. 1C). Notably, Schwann cells are one of the primary cell types that are pathologically affected in NF1 patients.

To identify which growth factors induce neurofibromin degradation, quiescent cells were treated with lysophosphatidic acid (LPA), platelet-derived growth factor (PDGF; Fig. 1D), or epidermal growth factor (EGF; Fig. 2A). In each case, neurofibromin levels were rapidly reduced, indicating that ligands that activate $G$ proteincoupled receptors or receptor tyrosine kinases can transduce signals leading to neurofibromin degradation. However, neurofibromin levels were re-elevated more rapidly in response to PDGF and EGF in comparison with LPA. Furthermore, degradation was typically less robust in response to EGF and PDGF versus LPA, suggesting that these receptor tyrosine kinases may couple less effectively to this regulatory mechanism. Notably, p120RasGAP has been shown to bind receptor tyrosine kinases following their activation and has therefore been proposed to regulate Ras downstream from these receptors (Donovan et al. 2002). Therefore, it is possible that p120RasGAP and neurofibromin play primary, but 


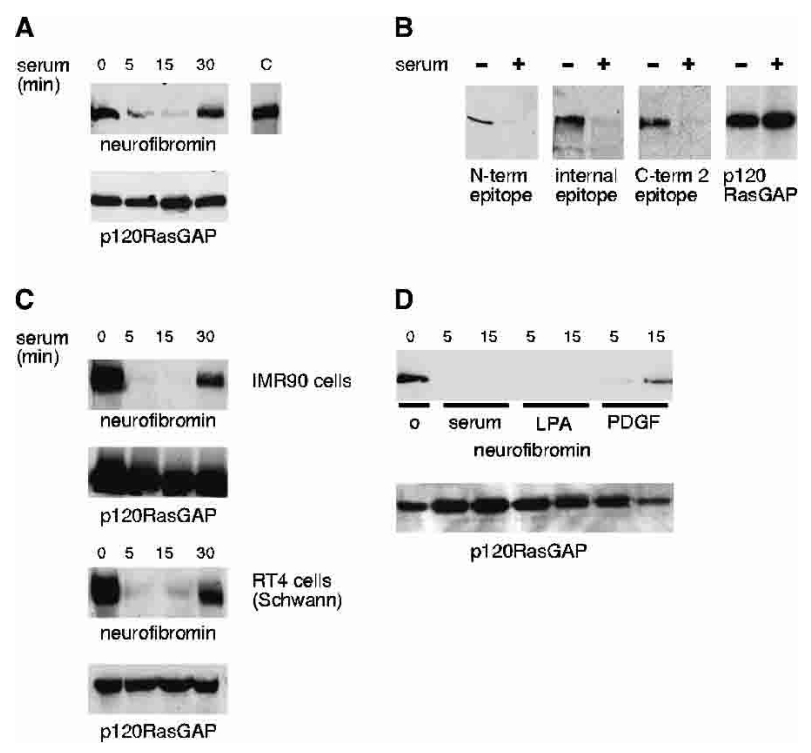

Figure 1. Neurofibromin is degraded in response to serum and growth factors. (A) Serum-starved NIH 3T3 cells were exposed to $10 \%$ serum for increasing lengths of time. Cells were lysed with $1 \%$ boiling SDS buffer and Western blots were probed with antibodies that recognize an epitope located in the $\mathrm{C}$ terminus of neurofibromin (top, NF1GRP-D) and an anti-p120RasGAP antibody (bottom). The lane labeled c (control) is full-length neurofibromin produced in baculovirus detected with the same neurofibromin antibody. (B) NIH 3 T3 cells were unstimulated or stimulated with serum for 5 min as described above, and Western blots were probed with either an N-terminal NF1 antibody (NF1GRP-N), an antibody that recognizes an internal epitope (GAP4), or an antibody that recognizes a second, distant C-terminal epitope (NF1C). The last blot was also reprobed with the p120RasGAP antibody. (C) IMR90 cells (top) or RT4 Schwannoma cells (bottom) were stimulated as described in $A$, and Western blots were probed with the NF1GRP-D antibody and the p120RasGAP antibody. $(D)$ Serum, LPA $(6 \mu M)$, and PDGF (20 ng/mL) were used to stimulate cells as described in $A-C$.

not exclusive roles in regulating Ras downstream of receptor tyrosine kinases and G protein-coupled receptors, respectively.

Ubiquitin-mediated proteolysis regulates a number of proteins involved in diverse cellular processes, such as cell cycle control, differentiation, and the immune response (Ciechanover et al. 2000). Degradation via the ubiquitin pathway involves the covalent attachment of ubiquitin molecules to a target protein on lysine residues, followed by its rapid degradation by the $26 \mathrm{~S}$ proteasome. To determine whether the proteasome was involved in regulating neurofibromin levels, NIH 3T3 cells were pretreated with the proteasome inhibitors LLnL or lactacystin prior to growth factor addition. Both agents inhibited the decrease in neurofibromin induced by LPA, PDGF, and EGF. The calpain inhibitor II (LLM) and the lysosomal inhibitor chlorquine did not affect neurofibromin levels (data not shown). To determine whether neurofibromin was a direct target of the ubiqitination machinery, cells were transfected with a plasmid encoding a His-tagged ubiquitin molecule and were treated with LLnL (Hofmann et al. 1996). His-tagged proteins were purified and analyzed by a Western blot probed with a neurofibromin antibody. A smear characteristic of ubiquitinated protein and break-down products was observed, demonstrating that neurofibromin is ubiquitinated in vivo (Fig. 2B). In addition, full-length baculovirus-expressed neurofibromin was also ubiquitinated when subjected to a well-characterized in vitro ubiquitination reaction, further demonstrating that it is a direct target of the ubiquitination machinery (Fig. 2C; Dai et al. 1998).

To identify the region within neurofibromin required for its degradation, full-length and FLAG-tagged protein fragments were produced and subjected to the in vitro ubiquitination and degradation assay (Fig. 3A). In the presence of proteasome inhibitors, neurofibromin was ubiquitinated in this in vitro assay and was degraded in their absence (Fig. 2C; data not shown). Notably, we found that a fusion protein encompassing the GAP-related domain and adjacent amino acids (GRD+80) was also degraded in an ATP-dependent manner in this assay. However, deletion of the $\mathrm{N}$-terminal 80 amino acids that lie outside of the GRD resulted in a degradation-resistant fragment (GRD). Importantly, the epitope tags of all fusion proteins were located at the $\mathrm{N}$ termini, eliminating

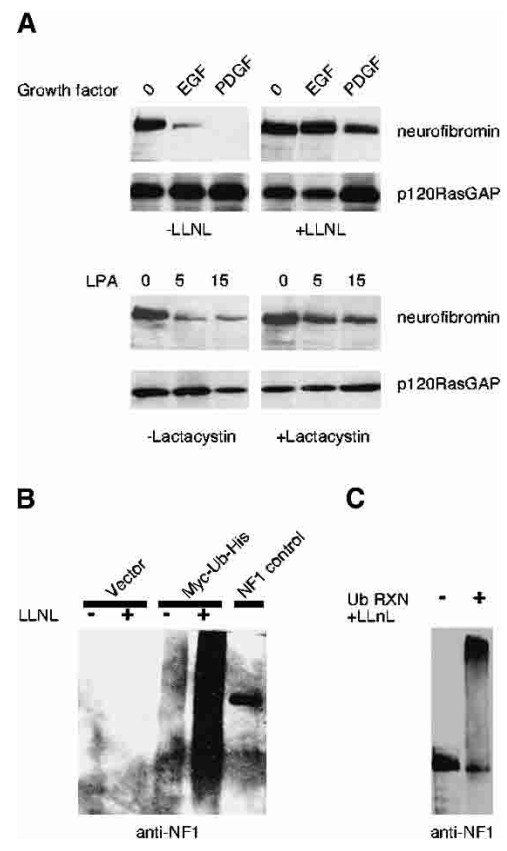

Figure 2. Neurofibromin is degraded by the proteasome. (A) Cells were untreated or pretreated with LLnL or lactacystin prior to EGF (5 min), PDGF (5 min), or LPA treatment for the times indicated, and Western blots were probed with the NF1GRP-D and p120RasGAP antibodies. (B) NIH 3T3 cells were transfected with a control plasmid or a plasmid encoding a His-tagged ubiquitin molecule. Twenty-four hours later, cycling cells were treated with LLnL where indicated, and Histagged proteins were purified using nickel-coupled agarose beads. Proteins were eluted, and a Western blot was probed with the C-terminal neurofbromin antibody. The NF1 control lane represents protein from a total cell lysate. $(C)$ Baculovirus-expressed full-length tagged neurofibromin was subjected to an in vitro ubiquitination reaction or a mock reaction in the presence of LLnL. A Western blot was probed with the NF1GRP-D antibody. 
any potential differences in protein stability due to the N-end rule (Baboshina et al. 2001).

To localize critical sequences within this protein fragment further, we produced a fusion protein containing the analagous Drosophila NF1 (DNF1) sequence, which exhibits $69 \%$ identity to the human protein in this region (The et al. 1997). Importantly, the Drosophila protein was similarly degraded in this assay, indicating that the sequences required for degradation are conserved among these species. Because the human and Drosophila fusion proteins exhibited the highest degree of similarity within the first 20 amino acids, we constructed a deletion mutant that eliminated these residues as well as various mutants containing internal triple alanine substitutions of conserved amino acids (Fig. 3B). Importantly, deletion of the first 20 amino acids resulted in a degradation-resistant fragment. Furthermore, mutation of residues 1095-1097 (KYF to AAA) or 1098-1100 (TLF to AAA) located within this region also inhibited degradation, indicating that these sequences are required for recognition by the degradation machinery. In addition, mutation of every serine, threonine, and tyrosine in the larger domain did not affect stability in this assay, and endogenous neurofibromin does not become phosphorylated following serum treatment (data not shown), suggesting that the protein does not require direct phosphorylation prior to degradation. Therefore, neurofibromin degradation appears to be unlike that of SCF substrates, in which phosphorylation of the E3 ubiquitin ligase-binding site is required for ubiquitination (Deshaies 1999). Regulation may therefore occur at the level of the ubiquitin ligase complex and/or associated proteins, as is the case for a variety of ubiquitinated substrates (Ciechanover et al. 2000). This regulation appears to be independent of Ras activation as exogenous expression of an activated Ras allele did not induce neurofibromin degradation and inhibitors of MEK and PI3-kinase did not prevent degradation (data not shown). To date, hundreds of E3 ubiquitin ligases are thought to exist in humans, each of which is predicted to ubiquitinate a restricted set of target proteins (Winston et al. 1999; Freemont 2000). The identification of an evolutionarily conserved domain within neurofibromin that is required

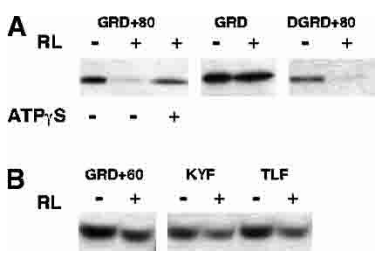

Figure 3. Sequences adjacent to the GRD are required for neurofibromin degradation. (A) FLAG-tagged fusion proteins encoding the GRD of human neurofibromin or the GRD plus $80 \mathrm{~N}$ terminal amino acids $(G R D+80)$ were generated by in vitro transcription and translation reactions (IVT) in the presence of ${ }^{35} \mathrm{~S}$ methionine. Proteins were subjected to a reticulocyte lysate (RL)-based in vitro degradation reaction in the presence of ATP or, where indicated, ATP $\gamma$, and separated by PAGE. A construct encoding the Drosophila GRD+80 protein was subjected to the same reaction (DGRD+80). (B) The GRD+80 construct was truncated to generate a GRD+60 construct that was used in the in vitro degradation assay. Alternatively, mutations resulting in triple alanine substitutions [1095-1097 (KYF to AAA) or 10981100 (TLF to AAA)] were introduced in the GRD+80 construct.

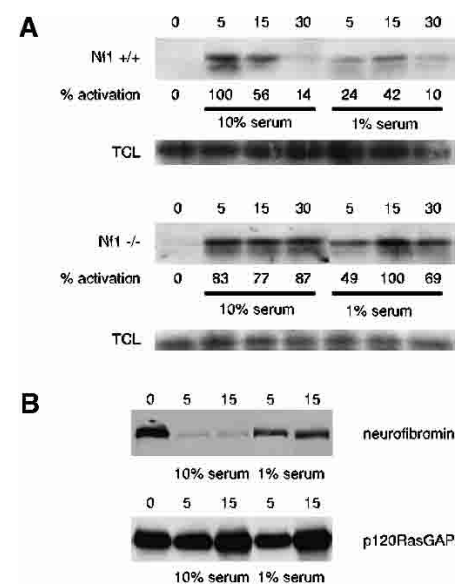

Figure 4. Nf1-deficient MEFs exhibit deregulated Ras activity. (A) Wild-type and Nf1-deficient MEFs were serum starved and treated with $10 \%$ or $1 \%$ serum for increasing lengths of time. Cells were lysed, and Ras-GTP was precipitated with a GSTRas-binding domain fusion protein. Western blots were probed with a pan-isoform-specific Ras antibody. Ras-GTP levels were quantitated using a densitometer and expressed as percentage of maximal levels. Total cell lysates from these samples were probed with the same antibody to ensure equal protein loading. (B) Total cell lysates were prepared from duplicate samples as described in $A$ and immunoblots were sequentially probed with an antineurofibromin antibody or an anti-p120RasGAP antibody.

for its recognition by the ubiquitin/proteasome machinery is an important first step toward identifying this ubiquitin ligase complex.

Because neurofibromin is a Ras-GAP, we next investigated how this dynamic regulation by the proteasome affected Ras signaling. When wild-type MEFs were treated with $10 \%$ serum, Ras-GTP levels were elevated within $5 \mathrm{~min}$ and significantly decreased by $30 \mathrm{~min}$ after treatment (Fig. 4A). As shown in Figures 1 and 2, neurofibromin protein levels were inversely related to this pattern of Ras activation, being degraded within $5 \mathrm{~min}$ and re-elevated within $30 \mathrm{~min}$ following exposure to $10 \%$ serum. In response to a nonmitogenic dose of serum (1\%) Ras-GTP levels were elevated with roughly similar kinetics in wild-type cells, but to much lower levels. Notably, in response to $1 \%$ serum, neurofibromin degradation was significantly less robust, suggesting that complete neurofibromin degradation is one of the signals required for maximal activation of Ras under these conditions (Fig. 4B). In contrast, in Nf1-deficient MEFs, both high and low concentrations of serum potently induced Ras activation (Fig. 4A). Furthermore, in both cases, RasGTP levels were sustained as compared with wild-type cells. These results demonstrate that neurofibromin is required to appropriately attenuate both the amplitude and duration of Ras activation. Specifically, our results suggest that the initial degradation of neurofibromin is required for full Ras activation, whereas its subsequent up-regulation is required to terminate this signal. Thus, in Nf1-deficient cells maximal, sustained Ras activation can be achieved independently of its regulation by the proteasome.

To examine how the differential activation of Ras in wild-type and Nf1-deficient MEFs affected downstream 
signaling pathways, we examined ERK activity. Whereas treatment with $10 \%$ serum caused a comparable activation of ERK in both wild-type and Nf1-deficient cells (Fig. 5A), low concentrations of serum induced a sustained activation of ERK in Nf1-deficient cells only (Fig. $5 B)$. Because the duration of ERK activity has been shown to be a critical determinant of cellular proliferation, we also examined the growth properties of wildtype and Nf1-deficient cells under these conditions (Fig. 5 C,D). Notably, in $10 \%$ serum there was no difference in the rate of proliferation between both cell types as determined by the slope of these two growth curves. This observation was consistent with the identical ERK activation profiles in response to $10 \%$ serum. However, Nf1deficient cells were able to proliferate in concentrations of serum that were nonmitogenic for wild-type cells. These results also mirrored the data shown in Figure 5A
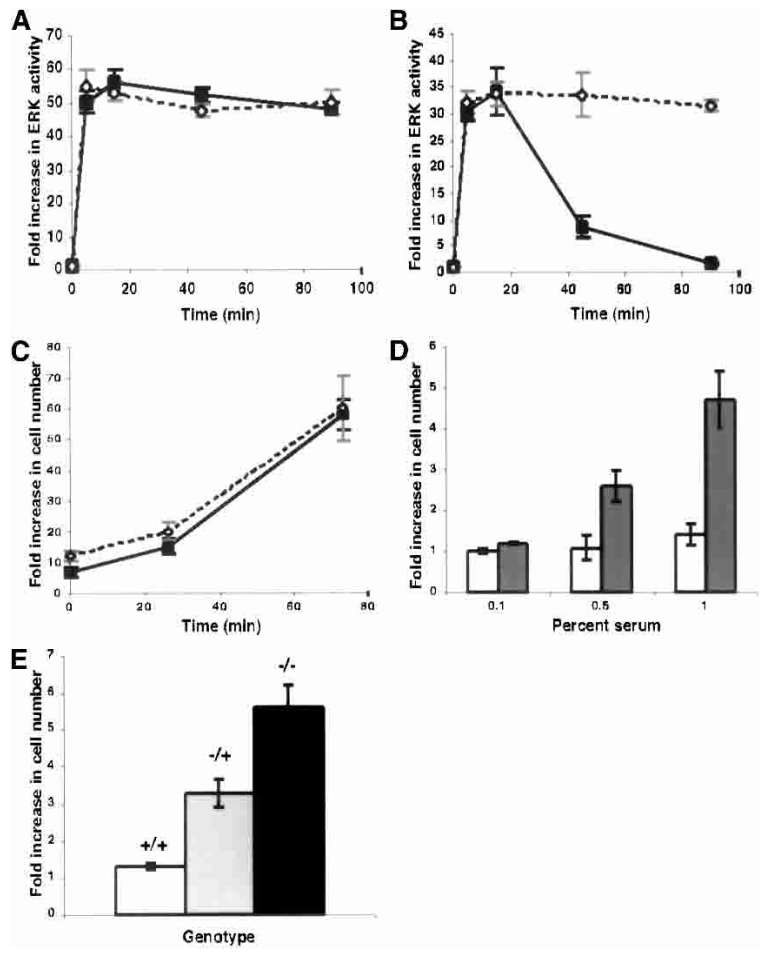

Figure 5. Nf1-deficient MEFs exhibit deregulated ERK activation and possess proliferation defects. $(A, B)$ Wild-type (solid line) and $N f 1$-deficient (broken line) MEFs were serum starved and treated with $10 \%(A)$ or $1 \%(B)$ serum for increasing lengths of time. ERK activation was measured using kinase assays performed in triplicate and quantitated using a PhosphorImager. (C) Wild-type and Nf1-deficient MEFS were serum starved and exposed to $10 \%$ serum. Cells from triplicate wells were counted on day 0 and at 25 and $72 \mathrm{~h}$ following serum treatment. $(D)$ Serum-starved wild-type (white bars) and mutant cells (gray bars) were treated with $0.1 \%, 0.5 \%$, or $1 \%$ serum. Cells in triplicate wells were counted $72 \mathrm{~h}$ after serum addition. Fold increase in cell number ratios were calculated as described in Materials and Methods. (E) Nf1+/+ (white bars), Nf1+/- (lightgray bars), and $N f 1-/-$ (black bars) MEFs were grown in $1 \%$ serum in triplicate wells for $72 \mathrm{~h}$ and analyzed as described in $D$. Differences in $B, D$, and $E$ as described in the text were found to be statistically significant at or better than $\alpha=0.01$ using a twotailed $\mathrm{T}$ test. and $\mathrm{B}$, in which low concentrations of serum induced a transient activation of ERK in wild-type cells, but elicited a more sustained activation of ERK in $N f 1$-deficient cells. Serum hypersensitivity was observed in every mutant cell line examined $1>10$ mutant and 10 wild-type lines). Consistent with the observation that neurofibromin is regulated at the level of protein expression, we also found that $\mathrm{Nf1+} /$ - cells exhibited an intermediate increased hypersensitivity to serum, suggesting that a growth advantage can also occur as a result of haploinsufficiency in these cells (Fig. 5E). Thus, our results provide important insight into the mechanism by which neurofibromin normally regulates the Ras pathway and proliferation.

The Ras-family of GTP-binding proteins are critical in transducing extracellular signals to the nucleus and mediate a wide variety of biological responses. Both positive and negative regulators of Ras activation have been identified (guanine nucleotide exchange factors and GAP proteins, respectively; Bollag and McCormick 1991; Quilliam et al. 1995). However, although the cell signaling mechanisms leading to the activation of exchange factors such as Sos have been well characterized /Chardin et al. 1993), the signals that regulate GAP proteins are less well known. Previous studies have demonstrated that the NF1 tumor suppressor gene product, neurofibromin, possesses Ras-GAP activity (Ballester et al. 1989; Martin et al. 1990; Xu et al. 1990). This study provides the first mechanistic insight into how growth factor receptors regulate this tumor suppressor and utilize it to control Ras activation and proliferation.

We have shown that at least two classes of receptors, $\mathrm{G}$ protein-coupled receptors and receptor tyrosine kinases, dynamically regulate neurofibromin protein levels via ubiquitin-mediated proteasomal degradation. Collectively, our data suggest that neurofibromin degradation participates in the initial activation of the Ras signaling pathway, whereas its rapid re-expression is required for appropriate attenuation of the pathway. Studies utilizing $N f 1$-deficient cells further demonstrate that neurofibromin is absolutely required for maintaining an appropriate sensitivity to growth factors and in regulating the duration of Ras and ERK activities. Neurofibromin's regulation of the Ras-ERK pathway appears to be critical under conditions in which growth factors are limiting. In response to saturating levels of growth factors, additional overriding mechanisms are likely to play a dominant role in sustaining ERK activation (Cai et al. 1997; Chaudhary et al. 2000; Nadal-Wollbold et al. 2002). Importantly, the duration of ERK activity has been shown to be critical in transducing a proliferative response in a number of experimental systems, supporting the notion that the defects observed in Nf1-deficient cells result from the lack of attenuation of this signal (Marshall 1995). This subtle growth advantage of NF1deficient cells may be particularly relevant in the development of the benign lesions that develop in NF1 patients.

Ubiquitin-mediated proteolysis has been shown to play a critical role in controlling the cell cycle /Ciechanover et al. 2000). This is achieved by the regulated accumulation and destruction of both positively acting components (e.g., cyclins) as well as cell cycle inhibitors (e.g., p27) in order to prevent premature cell cycle progression. The NF1 tumor suppressor may provide a similar function at the onset of the cell cycle by acting as a 
rheostat for Ras activation. Under mitogenic conditions, in which neurofibromin is rapidly and efficiently degraded, maximal Ras activation is permitted and proliferation ensues. However, in the absence of a threshold mitogenic signal, neurofibromin is not degraded, and any Ras activation is immediately dampened. Accordingly, in NF1-deficient cells a much lower threshold signal is required for maximal Ras activation and mitogenesis.

Finally, the identification of this regulatory mechanism may also have implications regarding disease treatment. Whereas complete loss of NF1 has been clearly implicated in the development of some NF1-related tumors (myeloid leukemia, pheochromocytoma), haplo-insufficiency due to a reduced dosage of the NF1 gene (NF1 patients are congenitally heterozygous for an NF1 mutation) is thought to underlie the development of other symptoms such as cognitive deficits, bone deformities, and peripheral nerve sheath tumors (Cichowski and Jacks 2001; Zhu et al. 2002). Thus, the identification of a pathway responsible for the regulated inactivation of neurofibromin may have important clinical implications, in that strategies aimed at blocking its inactivation and/or up-regulating the protein may prove to be beneficial therapeutically. These benefits may extend beyond therapies relevant to NF1 but may also serve as a potential clinical strategy to attenuate the Ras pathway in tumors harboring mutations in genes that function upstream of Ras.

\section{Materials and methods}

Cell culture and immunoblots

NIH3T3, IMR90, or RT4 cells were plated in serum-free medium at a density of $5 \times 10^{5}$ cells $/ 10$-cm plate. After $18 \mathrm{~h}, 10 \%$ serum, $6 \mu \mathrm{M} \mathrm{LPA}$ $20 \mathrm{ng} / \mathrm{mL}$ EGF, or $20 \mathrm{ng} / \mathrm{mL}$ PDGF was added. Cells were lysed with $1 \%$ SDS boiling lysis buffer and clarified. Lysates were normalized for protein levels and analyzed by Western blotting with the following antineurofibromin antibodies: NF1GRP-D and NF1GRP-N (Santa Cruz Biotechnology), GAP4, an antibody directed toward an alternative spliced region within the GRD (Huynh et al. 1994), or the NF1C antibody directed toward an epitope $>300$ amino acids away from that recognized by NF1GRP-D (Huynh et al. 1994). Blots were also reprobed with an antip120RasGAP antibody (Transduction Laboratories). When indicated, cells were pretreated with $50 \mu \mathrm{M} \mathrm{N}$-Acetyl-leu-leu-norleu-al (LLnL) for 4-8 h, and $20 \mu \mathrm{m}$ lactacystin for 4-8 h.

Detection of ubiquitinated neurofibromin in vivo

NIH 3T3 cells were transfected with a control plasmid or a plasmid encoding a His-tagged ubiquitin molecule (pRBG4-his6-myc-Ub). Twenty-four hours later, cycling cells were treated with LLnL. To enrich for ubiquitinated neurofibromin, five 10-cm plates per condition were lysed with RIPA buffer, and His-tagged proteins were purified using nickel-coupled agarose beads. Proteins were eluted, and a Western blot was probed with the neurofbromin antibody.

Generation of mutant constructs

All FLAG-tagged GRD constructs were generated by PCR amplification of the human NF1 cDNA and followed by subcloning into pCMV-TAG vectors. Point mutants were generated by Quick Change (Stratagene). All final sequences were verified.

In vitro ubiquitination/degradation assay

For degradation assays, protein fragments encoding the NF1-GRD and mutants were generated by IVT reactions (Promega) in the presence of ${ }^{35} \mathrm{~S}$-methionine. Radiolabeled proteins were then subjected to a reticulocyte lysate (RL)-based in vitro degradation reaction as described previously and separated by PAGE (Dai et al. 1998). Briefly, $4 \mu \mathrm{L}$ of the IVT product was incubated with $16.5 \mu \mathrm{L}$ of RL in degradation buffer containing $50 \mathrm{mM}$ Tris ( $\mathrm{pH} 7.5$ ), $5 \mathrm{mM} \mathrm{MgCl}_{2}, 1 \mu \mathrm{M}$ DTT, $5 \%$ glycerol, and 1 $\mathrm{mg} / \mathrm{mL}$ ubiquitin for $90 \mathrm{~min}$ at $37^{\circ} \mathrm{C}$ in the presence of ATP or ATP $\gamma$. In experiments in which full-length baculovirus neurofibromin was used in this reaction, a Western blot was probed with the NF1GRP-D antibody. Ubiquitination assays were carried out in the same way but in the presence of $50 \mu \mathrm{M}$ LLnL.

\section{Proliferation studies}

MEFs were made quiescent as described previously (Brugarolas et al. 1998), split to a density equivalent to $5 \times 10^{5}$ cells $/ 10$-cm plate in triplicate, and then stimulated with serum. After the indicated time, cells were trypsinized and counted. Where indicated, fold increase in cell number ratios were calculated by dividing the average cell number of three plates in serum at $72 \mathrm{~h}$ by the average cell number of three plates in serum-free medium after $18 \mathrm{~h}$ (at this point there was little, if any, cell death). The standard deviation of these data were calculated using the standard curve method defined by the following formula $\left[\left(\mathrm{SD}_{1} /\right.\right.$ $\left.\left.\operatorname{Avg}_{1}\right)^{2}+\left(\mathrm{SD}_{2} / \operatorname{Avg}_{2}\right)^{2}\right]^{1 / 2} \times \operatorname{Avg}_{\text {ratio }}$. Proliferation studies were performed in more than 10 cell lines of each genotype and gave similar results.

\section{Ras and ERK activation analysis}

MEFs were made quiescent and stimulated as described above. Lysates were normalized and Ras-GTP was detected using a Ras-activation assay kit according to the manufacturer's instructions (Upstate Biotechnology). ERK activity was measured by a kinase assay as described previously. Briefly, cells were stimulated as described above and lysed in RIPA buffer. Protein levels were normalized, and ERK1 was immunoprecipitated. Kinase assays were performed using $7 \mu \mathrm{g}$ of myelin basic protein as a substrate in the presence of $3 \mu \mathrm{Ci}\left[\gamma^{-}{ }^{32} \mathrm{P}\right] \mathrm{ATP}$. Incorporation of $\left[{ }^{32} \mathrm{P}\right]$ was quantified using a PhosphorImager. All kinase assays were done in triplicate.

\section{Acknowledgments}

We thank D. Livingston for the pRBG4-his6-myc-Ub; G. Bollag for the NF1 GRD cDNA and baculovirus-produced full-length neurofibromin; A. Bernards for the DNF1 cDNA; C. Park, L. Greer, S. Thomas, and members of the Jacks and Cichowski laboratories for helpful discussions; E. Jackson for mouse embryonic fibroblasts; J. Kissel for RT4 cells; C. Brannan and J. Duong for the GAP4 and NF1C antibodies; and M. Bulyk for statistical analysis. Supported in part by grants from the Department of the Army, the Medallion Foundation, and the American Cancer Society. K.C. was supported by a National Neurofibromatosis Foundation Young Investigator Award and a Research Scholar Grant from the American Cancer Society. T.J. is an Investigator at the Howard Hughes Medical Institute.

The publication costs of this article were defrayed in part by payment of page charges. This article must therefore be hereby marked "advertisement" in accordance with 18 USC section 1734 solely to indicate this fact.

\section{References}

Baboshina, O.V., Crinelli, R., Siepmann, T.J., and Haas, A.L. 2001. N-end rule specificity within the ubiquitin/proteasome pathway is not an affinity effect. J. Biol. Chem. 7: 7.

Ballester, R., Michaeli, T., Ferguson, K., Xu, H.P., McCormick, F., and Wigler, M. 1989. Genetic analysis of mammalian GAP expressed in yeast. Cell 59: 681-686.

Basu, T.N., Gutmann, D.H., Fletcher, J.A., Glover, T.W., Collins, F.S., and Downward, J. 1992. Aberrant regulation of ras proteins in malignant tumour cells from type 1 neurofibromatosis patients Nature 356: 713-715

Bollag, G. and McCormick, F. 1991. Differential regulation of rasGAP and neurofibromatosis gene product activities. Nature 351: 576-579.

Bollag, G., Clapp, D.W., Shih, S., Adler, F., Zhang, Y.Y., Thompson, P., Lange, B.J., Freedman, M.H., McCormick, F., Jacks, T., et al. 1996. Loss of NF1 results in activation of the Ras signaling pathway and leads to aberrant growth in haematopoietic cells. Nat. Genet. 12: 144-148.

Boyer, M.J., Gutmann, D.H., Collins, F.S., and Bar-Sagi, D. 1994. Crosslinking of the surface immunoglobulin receptor in B lymphocytes induces a redistribution of neurofibromin but not p120-GAP. Oncogene 9: 349-357.

Brannan, C.I., Perkins, A.S., Vogel, K.S., Ratner, N., Nordlund, M.L., 
Reid, S.W., Buchberg, A.M., Jenkins, N.A., Parada, L.F., and Copeland, N.G. 1994. Targeted disruption of the neurofibromatosis type-1 gene leads to developmental abnormalities in heart and various neural crest-derived tissues Genes \& Dev. 8: 1019-1029.

Brugarolas, J., Bronson, R.T., and Jacks, T. 1998. p21 is a critical CDK2 regulator essential for proliferation control in Rb-deficient cells. $J$. Cell. Biol. 141: 503-514.

Cai, H., Smola, U., Wixler, V., Eisenmann-Tappe, I., Diaz-Meco, M.T., Moscat, J., Rapp, U., and Cooper, G.M. 1997. Role of diacylglycerolregulated protein kinase $\mathrm{C}$ isotypes in growth factor activation of the Raf-1 protein kinase. Mol. Cell. Biol. 17: 732-741.

Cawthon, R.M., Weiss, R., Xu, G.F., Viskochil, D., Culver, M., Stevens, I., Robertson, M., Dunn, D., Gesteland, R., O'Connell, P., et al. 1990 A major segment of the neurofibromatosis type 1 gene: cDNA sequence, genomic structure, and point mutations. Cell 62: 193-201.

Chardin, P., Camonis, J.H., Gale, N.W., van Aelst, L., Schlessinger, J., Wigler, M.H., and Bar-Sagi, D. 1993. Human Sos1: A guanine nucleotide exchange factor for Ras that binds to GRB2. Science 260: 13381343.

Chaudhary, A., King, W.G., Mattaliano, M.D., Frost, J.A., Diaz, B., Morrison, D.K., Cobb, M.H., Marshall, M.S., and Brugge, J.S. 2000. Phosphatidylinositol 3-kinase regulates Raf1 through Pak phosphorylation of serine 338. Curr. Biol. 10: 551-554.

Cichowski, K. and Jacks, T. 2001. NF1 tumor suppressor gene function: Narrowing the GAP. Cell 104: 593-604.

Ciechanover, A., Orian, A., and Schwartz, A.L. 2000. Ubiquitin-mediated proteolysis: Biological regulation via destruction. BioEssays 22: 442451.

Dai, Z., Quackenbush, R.C., Courtney, K.D., Grove, M., Cortez, D., Reuther, G.W., and Pendergast, A.M. 1998. Oncogenic Abl and Src tyrosine kinases elicit the ubiquitin-dependent degradation of target proteins through a Ras-independent pathway. Genes \& Dev. 12: 1415-1424.

DeClue, J.E., Papageorge, A.G., Fletcher, J.A., Diehl, S.R., Ratner, N., Vass, W.C., and Lowy, D.R. 1992. Abnormal regulation of mammalian p21ras contributes to malignant tumor growth in von Recklinghausen (type 1) neurofibromatosis. Cell 69: 265-273.

Deshaies, R.J. 1999. SCF and Cullin/Ring H2-based ubiquitin ligases. Annu. Rev. Cell. Dev. Biol. 15: 435-467.

Donovan, S., Shannon, K.M., and Bollag, G. 2002. GTPase activating proteins: Critical regulators of intracellular signaling. Biochim. Biophys. Acta 1602: 23-45.

Freemont, P.S. 2000. RING for destruction? Curr. Biol. 10: R84-R87.

Han, J.W., McCormick, F., and Macara, I.G. 1991. Regulation of Ras-GAP and the neurofibromatosis-1 gene product by eicosanoids. Science 252: $576-579$.

Hofmann, F., Martelli, F., Livingston, D.M., and Wang, Z. 1996. The retinoblastoma gene product protects E2F-1 from degradation by the ubiquitin-proteasome pathway. Genes \& Dev. 10: 2949-2959.

Huynh, D.P., Nechiporuk, T., and Pulst, S.M. 1994. Differential expression and tissue distribution of type I and type II neurofibromins during mouse fetal development. Dev. Biol. 161: 538-551.

Jacks, T., Shih, T.S., Schmitt, E.M., Bronson, R.T., Bernards, A., and Weinberg, R.A. 1994. Tumour predisposition in mice heterozygous for a targeted mutation in Nf1. Nat. Genet. 7: 353-361.

Kim, H.A., Rosenbaum, T., Marchionni, M.A., Ratner, N., and DeClue, J.E. 1995. Schwann cells from neurofibromin deficient mice exhibit activation of p21ras, inhibition of cell proliferation and morphological changes. Oncogene 11: 325-335.

Marshall, C.J. 1995. Specificity of receptor tyrosine kinase signaling: Transient versus sustained extracellular signal-regulated kinase activation. Cell 80: 179-185.

Martin, G.A., Viskochil, D., Bollag, G., McCabe, P.C., Crosier, W.J. Haubruck, H., Conroy, L., Clark, R., O'Connell, P., Cawthon, R.M., et al. 1990. The GAP-related domain of the neurofibromatosis type 1 gene product interacts with ras p21. Cell 63: $843-849$.

Nadal-Wollbold, F., Pawlowski, M., Levy-Toledano, S., Berrou, E., Rosa, J.P., and Bryckaert, M. 2002. Platelet ERK2 activation by thrombin is dependent on calcium and conventional protein kinases $\mathrm{C}$ but not Raf-1 or B-Raf. FEBS Lett. 531: 475-482.

Quilliam, L.A., Khosravi-Far, R., Huff, S.Y., and Der, C.J. 1995. Guanine nucleotide exchange factors: Activators of the Ras superfamily of proteins. BioEssays 17: 395-404.
Riccardi, V.M. 1992. Neurofibromatosis: Phenotype, natural history, and pathogenesis. The Johns Hopkins University Press, Baltimore, MD and London, UK.

The, I., Hannigan, G.E., Cowley, G.S., Reginald, S., Zhong, Y., Gusella, J.F., Hariharan, I.K., and Bernards, A. 1997. Rescue of a Drosophila NF1 mutant phenotype by protein kinase A. Science 276: 791-794.

Wallace, M.R., Marchuk, D.A., Andersen, L.B., Letcher, R., Odeh, H.M., Saulino, A.M., Fountain, J.W., Brereton, A., Nicholson, J., Mitchell, A.L., et al. 1990. Type 1 neurofibromatosis gene: Identification of a large transcript disrupted in three NF1 patients. Science 249: 181186.

Winston, J.T., Koepp, D.M., Zhu, C., Elledge, S.J., and Harper, J.W. 1999. A family of mammalian F-box proteins. Curr. Biol. 9: 1180-1182.

Xu, G.F., Lin, B., Tanaka, K., Dunn, D., Wood, D., Gesteland, R., White, R., Weiss, R., and Tamanoi, F. 1990. The catalytic domain of the neurofibromatosis type 1 gene product stimulates ras GTPase and complements ira mutants of S. cerevisiae. Cell 63: 835-841.

Zhang, Y.Y., Vik, T.A., Ryder, J.W., Srour, E.F., Jacks, T., Shannon, K. and Clapp, D.W. 1998. Nf1 regulates hematopoietic progenitor cell growth and ras signaling in response to multiple cytokines. J. Exp. Med. 187: 1893-1902.

Zhu, Y., Ghosh, P., Charnay, P., Burns, D.K., and Parada, L.F. 2002 Neurofibromas in NF1: Schwann cell origin and role of tumor environment. Science 296: 920-922. 


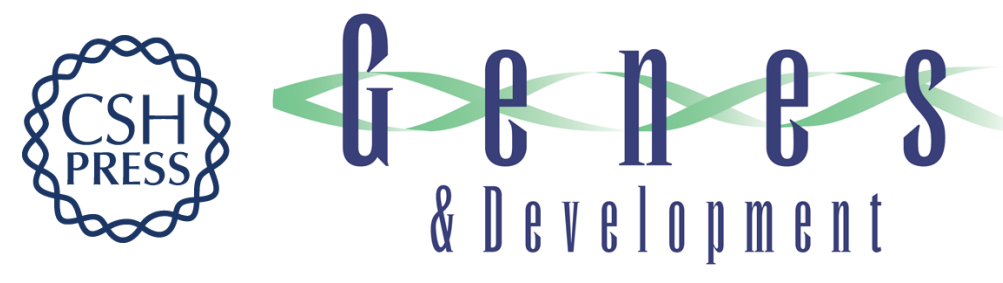

\section{Dynamic regulation of the Ras pathway via proteolysis of the NF1 tumor suppressor}

Karen Cichowski, Sabrina Santiago, Melanie Jardim, et al.

Genes Dev. 2003, 17:

Access the most recent version at doi:10.1101/gad.1054703

References This article cites 33 articles, 11 of which can be accessed free at: http://genesdev.cshlp.org/content/17/4/449.full.html\#ref-list-1

\section{License}

Email Alerting

Receive free email alerts when new articles cite this article - sign up in the box at the top Service right corner of the article or click here.

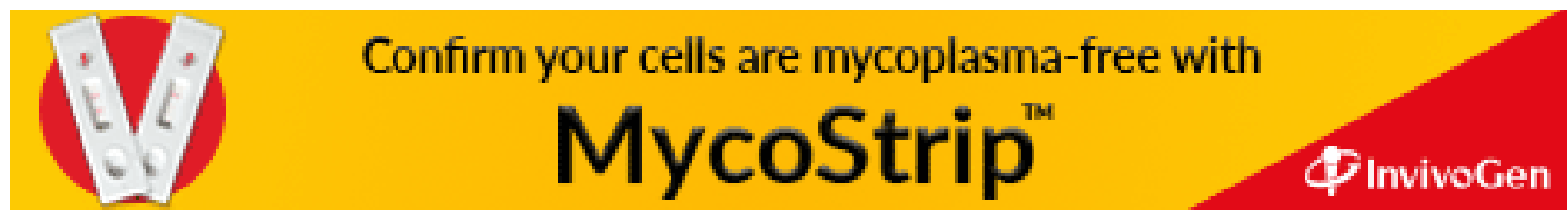

